\title{
LA FUNCIÓN JUDICIAL EN EL MARCO DEL ESTADO SOCIAL Y AUTONÓMICO ESPAÑOL: ¿PODER O SERVICIO PÚBLICO ${ }^{1}$
}

\author{
Ciro Milione
}

Sumario: 1. Justicia y Estado en El Pensamiento de MontesQuieu. 2. LA CONSTITUCIONALIZACIÓN DE LA FUNCIÓN JURISDICCIONAL EN LA CONSTITUCIÓN ESPAÑOLA (CE) DE 1978. 2.1. Los principios constitucionales que rigen la función jurisdiccional en la CE. 2.1.1. El principio de legitimación democrática del Poder Judicial y de sumisión del juez a la Ley. 2.1.2. El principio de responsabilidad. 2.1.3. El principio de exclusividad. 2.1.4. El principio de unidad de la jurisdicción y la dimensión territorial del Poder Judicial en nuestro Estado Autonómico. 3. LA NECESIDAD DE JUSTICIA EN NUESTRAS SOCIEDADES DEMOCRÁTICAS ACTUALES. 3.1. Estado Social y función judicial. 3.2. ¿Es el Poder Judicial un verdadero poder público? Hacia una nueva configuración de la Administración de Justicia. 4. CONCLUSIONES. LA JUSTICIA: UN SERVICIO PÚBLICO ESENCIAL.

«La Justicia es la verdad en acción»

Joseph Joubert

\section{JUSTICIA Y ESTADO EN EL PENSAMIENTO DE MONTESQUIEU}

Examinar el pensamiento de MoNTESQUIEU, eminente filósofo y jurista francés, constituye una premisa imprescindible para entender la posición del Poder Judicial en el marco de un Estado democrático y para poder analizar, desde una perspectiva histórica, nuestras realidades constitucionales.

Núcleo esencial del pensamiento de MoNTESQUIEU es la obediencia a la Ley, interpretada como un camino hacia la permanencia del Estado. En este

${ }^{1}$ Quiero formular mis más profundos agradecimientos a los Profs. Pablo Lucas Murillo de la Cueva, Miguel J. Agudo Zamora y Luis I. Gordillo Pérez por sus inestimables aportaciones que enriquecen ahora este trabajo y por su amable labor de revisión. Cualquier error, omisión o imprecisión es exclusivamente imputable al autor. 
sentido, el filósofo afirma «la virtud cívica consiste en el deseo de ver el orden establecido en el Estado, en el sentir felicidad por la tranquilidad pública, por la exacta administración de la Justicia, por la seguridad de la magistratura, por el respeto tributado a las leyes, por la estabilidad de la República.»²

Con el fin de garantizar dicha permanencia y estabilidad y, en definitiva para asegurar la libertad del ciudadano respecto a los demás ciudadanos y a los que ostentan un Poder estatal, MoNTESQUIEU identifica, en toda organización política estable, tres Poderes distintos ( $"$ Hay en todos los Estados tres especies de Poder: el legislativo, el de ejecutar aquello que depende del derecho de gentes y el de ejecutar lo que depende del derecho civil») e inmediatamente después postula su neta separación ${ }^{3}$.

Sin embargo, la división de Poderes de MonTESQuiEu se presta a interpretaciones diversas, haciendo de esta teoría sin duda una «obra grande» pero a la vez «ambigua» ${ }^{4}$.

Como señala BARBERIS ${ }^{5}$, es posible distinguir, por lo menos, tres lecturas distintas del pensamiento del ilustre filósofo francés: una primera tesis que describe como "distinción de Poderes»; una segunda definida "equilibrio entre Poderes»; una tercera descrita como «separación de Poderes en sentido estricto» ${ }^{6}$.

${ }^{2}$ Montesquieu, C.-L. de S., Del espíritu de las leyes, Librería General de Victoriano Suárez, Madrid, 1906. Sobre las tesis del conocido pensador, señalamos SANTAELLA LóPEZ, M., Montesquieu: el legislador y el arte de legislar, Universidad Pontificia Comillas, 1995; Vallet De Goytisolo, J. B., Montesquieu, leyes, gobiernos y poderes, Cívitas, Madrid, 1986; IGLesias, C., El pensamiento de Montesquieu: ciencia y filosofía en el siglo XVIII, Círculo de Lectores, Galaxia Gutenberg, Barcelona, 2005.

3 Afirma Montesquieu, «Todo estaría perdido si el mismo hombre, o el mismo cuerpo de los próceres o de los nobles o del pueblo, ejerciese estos tres Poderes: el de hacer las leyes, el de ejecutar las resoluciones públicas y el de juzgar los delitos o las diferencias de los particulares», Del espíritu..., ob. cit., p. 228.

${ }^{4}$ Como quiso poner en evidencia TARello, G., Storia della cultura giuridica moderna, Vol. I, Assolutismo e codificazione del diritto, Il Mulino, Bologna, 1998, p. 262.

${ }_{5}$ BARBERIS, M., «Separazione dei poteri e teoria giusrealista dell'interpretazione» en, Comanducci, P., Guastini, R. (coord.), Analisi e diritto 2004, pp. 2-8.

${ }^{6}$ Así, BARBERIS describe la tesis de MONTESQUIEU, en primer lugar, como una teoría de la «distinción de Poderes». En este sentido, el pensador francés pretende sencillamente describir tres funciones del Estado que destacan por determinadas características: la función de producción normativa que se define como «libre»; la función de ejecución normativa, descrita como «discrecional»; y finalmente la función de aplicación normativa con su carácter «vinculante». Interpretado en este sentido el pensamiento de MONTESQUIEU encuentra su principal opositor en H. KELSEN que reconoce exclusivamente las funciones de creación y aplicación normativa y subordina la segunda a la primera (KELSEN, H., Teoria generale del diritto e dello Stato, Etas, Milano, 1966, pp. 274-287).

Una segunda lectura de la tesis de MONTESQUIEU es la que interpreta como la teoría de los «equilibrios entre poderes». En otras palabras, las tres funciones estatales estarían repartidas entre otros muchos órganos, capaces de contrabalancearse. Es esta la interpreta- 
Con el fin de apreciar y definir el perímetro y los contornos propios del Poder Judicial, el jurista italiano se acerca a esta tercera teoría describiendo cómo la división de Poderes de MonTESQuieu, en realidad, describe un mecanismo de atribución de funciones estatales a órganos diversos.

En este sentido y basándose en la letra del Capítulo VI del Libro XI ( «El poder de juzgar») de "El espiritu de las leyes», BARBERIS afirma que una verdadera separación es exclusivamente la que atañe al Poder Judicial. En efecto, mientras los órganos legislativos y ejecutivos participan de modo excepcional a las funciones jurisdiccionales, los órganos judiciales jamás participan en las funciones legislativas o ejecutivas.

Por ello, BARBERIS puede afirmar que «el Poder Judicial, en MONTESQUIEU, es el único Poder por el que vale el criterio técnico de la especialización de las funciones, característico de la doctrina de la separación de los Poderes en sentido estricto, y también el único respecto al cual encontrarán aplicación las teorías montesquianas al comienzo de la Revolución ${ }^{7}$.

Asimismo, cabe destacar cómo el ejercicio del Poder Judicial, en el pensamiento de MonTESQuieu, no debe ser atribuido a profesionales o burócratas, sino a jueces populares, de modo que dicho Poder «tan terrible entre los hombres, sin estar relacionado a una determinada condición profesional, deviene invisible y nulo. No se tiene continuamente a los jueces ante los ojos y se teme a la magistratura y no a los magistrados $\rangle^{8}$.

De esta manera, MONTESQUIEU puede describir el Poder Judicial como «un Poder nulo", porque confiado a ciudadanos comunes, $\mathrm{y}$, en su utópica visión de la administración de Justicia, el filósofo francés puede llegar a afirmar que «los jueces de la Nación no son, según sabemos, sino la boca por donde habla la Ley, seres inanimados que no pueden moderar ni su fuerza ni su rigor»?.

ción más coherente tomando en consideración la letra del Capítulo IV del Libro XI, ahí donde el filósofo francés, después de haber admitido que «todo hombre investido de autoridad propende a abusar de ella» afirma «para que no pueda abusarse del poder es preciso que, por la disposición de las cosas, el poder contenga al poder» (Del espíritu..., ob. cit., p. 225). En este sentido, para BARBERIS, MonTESQUIEU atribuye el Poder Legislativo y el Poder Ejecutivo a dos órganos «no especializados», es decir, a dos órganos capaces de intervenir uno en las tareas del otro, para que a través de un ejercicio concertado de sus funciones esté garantizado un suficiente equilibrio entre Poderes. Por último, en esta interpretación de la tesis de MontesQuieu, el Poder Judicial representa la única función dotada de un «carácter de especialización» y por lo tanto ajena a toda intromisión perpetrada por parte de otros Poderes. En este sentido, para BARBERIS, todo deja pensar que MONTESQUIEU configurara el Poder Judicial como un verdadero «contrapoder».

7 Cfr. BARBeris, M., Benjamin Constant. Rivoluzione, costituzione, progresso, Il Mulino, Bologna, 1988, pp. 122 ss.; siempre del mismo autor., I limiti del potere: il contributo francese, en Duso, G. (coord.), Il potere. Per la storia della filosofia politica moderna, Carocci, Roma, 1999, pp. 214-224.

${ }^{8}$ Del espíritu..., ob. cit., p. 229.

9 Del espíritu..., ob. cit., p. 237. 
El pensamiento de MonTESQUiEU, como es sabido, ha influido en manera determinante en la consolidación del constitucionalismo moderno.

Es significativo que la teoría de la división de Poderes, así como adoptada por los constituyentes revolucionarios de Norteamérica (1787) y Francia (1789-91), así es aun hoy recogida en las principales Constituciones de los Estados democráticos europeos.

Es muy interesante dar cuenta de esta influencia, y por ello, a continuación, queremos describir cómo la función jurisdiccional ha sido constitucionalizada en nuestra Constitución de 1978 (a partir de ahora CE).

\section{LA CONSTITUCIONALIZACIÓN DE LA FUNCIÓN JURISDICCIONAL EN LA CE DE 1978}

La Constitución de 1978 regula la materia judicial preeminentemente ${ }^{10} \mathrm{en}$ su Título VI (Arts. 117-127), rubricado «Poder Judicial».

Es evidente que, recurriendo a esta acepción -la de «Poder»-, el Constituyente español ${ }^{11}$ adopta una expresión formalmente distinta respecto a las que se emplean en otras muchas Constituciones europeas ${ }^{12}$ para regular la misma materia.

${ }^{10}$ En efecto, el concepto de Justicia es recurrente en el dictado constitucional, como valor (es suficiente señalar cómo el mismo Preámbulo establece que «la Nación española, deseando establecer la justicia, la libertad y la seguridad...»; asimismo el art. 1.1 señala como valores superiores del ordenamiento jurídico «la libertad, la justicia, la igualdad, y el pluralismo político»); como derecho fundamental (véase por ejemplo el art. 24, relativo a la tutela judicial efectiva, pero también el art. 17, relativo al derecho a la libertad personal), como Poder del Estado (véase el art. 117), como estructura organizada (véase el art. 122), y como servicio público dentro del esquema de reparto competencial entre Estado y Comunidades Autónomas (véase el art. 149.1.5). LóPEZ AgUILAR, J. F., Justicia y Estado Autonómico, Civitas, Madrid, 1994; La Justicia y sus problemas en la Constitución, Tecnos, Madrid, 1996; y «Justicia y Poder Judicial: radiografía de una crisis cronificada», en Nuevas Políticas Públicas: Anuario multidisciplinar para la modernización de las Administraciones Públicas, núm. 5, 2009, p. 11.

11 Interesante es recordar como en la Sesión de la Ponencia de Constitución celebrada el día 2 de noviembre de 1977, sólo el representante de Alianza Popular, D. Manuel Fraga Iribarne, manifestó algunas reservas de carácter técnico en cuanto al empleo de la expresión «Poder Judicial». Vd. «Las actas de la ponencia constitucional», en Revista de las Cortes Generales, núm. 2, 1984, p. 306.

12 Pensemos al caso alemán y al Capítulo IX de la Ley Fundamental para la República Federal de 1949, rubricado «Die Rechtsprechung» (que podría traducirse con «La Jurisdicción»); o al caso de la Constitución Francesa cuyo Título VIII tiene por epígrafe «De l'Autorité Judiciaire» («De la Autoridad Judicial»). Valga particularmente el ejemplo de la Constitución Italiana. Como es sabido, el Constituyente italiano decidió no emplear la expresión «Poder Judicial» para indicar el conjunto de órganos e instituciones encargados de desarrollar la función judicial -al contrario de lo que ocurrirá 30 años después en España- sino que adoptó un término más genérico, «Magistratura», como testimonia el epígrafe del Título IV («La Magistratura») o el primer apartado del art. 104. 
Actuando así, el texto fundamental de este país retoma una expresión no se había vuelto a utilizar desde la Constitución de 1869, cuyo art. 36 declaraba «Los tribunales ejercen el Poder Judicial» y cuyo Título VII llevaba por epígrafe «Del Poder Judicial» ${ }^{13}$.

Significativo, en este sentido, fue el debate que se desató, en seno a la Asamblea Constituyente, al momento de determinar la exacta colocación de la función judicial en el esquema constitucional italiano.

En esta labor, el pensamiento de MonTESQUIEU y su teoría de la separación de Poderes fue tenido en constante consideración e interpretado con el fin de asegurar, en el marco del principio de sumisión a la Ley y al ordenamiento jurídico, la máxima autonomía y libertad para la función judicial a través de una serie de garantías subordinadas sólo a la sumisión de los jueces a la Ley y al Estado de Derecho.

En este sentido, como evidenció RUINI (Le confessioni pel domani (da un ultraottuagenario), Ricordi di pensiero e di vita e per la storia di domani, escrito inedito guardado en el Archivio Meuccio Ruini, Biblioteca «Panizzi»-Reggio Emilia), miembro de la asamblea constituyente, la elección del término «Magistratura» se debió a la voluntad de identificar un conjunto de individuos responsables del ius dicere, sin con ello cuestionar la verdadera naturaleza de la función judicial interpretada como un verdadero Poder del Estado.

En efecto, para defender dicha tesis, RuINI recordó cómo incluso en los casos del Poder Legislativo y Ejecutivo se había optado por evitar el recurso al término «Poder» a favor de expresiones distintas como «Parlamento» y «Gobierno», sin que con esto se cuestionara la verdadera naturaleza de estas funciones, es decir, la de Poderes del Estado.

Asimismo el diputado remarcó la independencia de la Magistratura al sostener que «afirmando que un determinado orden, el orden de la Magistratura, debe ser independiente, es decir, no debe depender de otro Poder del Estado, y que debe ser autónomo, es decir, disponer de sí para lo que concierne a su estado, como personal de los magistrados, no afirmamos que no sea constitucional y democrático. Que la Magistratura esté desvinculada de la dependencia y influencia del Gobierno es una exigencia y una conquista de la democracia».

Si bien es cierto que gran parte de la Asamblea Constituyente aceptó esta tesis, otros miembros se mantuvieron en posiciones antitéticas.

En particular, destaca entre todas ellas, la posición de PRETI que apoyó la decisión de no rubricar el Título IV como «Poder Judicial» considerando, entre otras cosas, la función judicial ya no como un Poder sino como un verdadero servicio público. En este sentido, en la sesión antemeridiana celebrada el día 25 de noviembre de 1947, el diputado PrETI tomó la palabra para afirmar que «hoy me parece que los magistrados deban considerarse al servicio del Estado, así como todos los demás funcionarios, si bien es cierto que su posición se debe considerar como particular [...] ellos desarrollan una función delicada, y por lo tanto su independencia debe estar garantizada, pero no se debe llegar a declarar en la Constitución que constituyen un orden autónomo e independiente. Decir esto quiere decir reconocerles un pleno autogobierno, casi como si se quisiera crear un Estado en el Estado, o por lo menos una casta cerrada, intangible». (Para consultar las actas de la Asamblea Constituyente señalamos un excelente recurso en línea a la página web $<\mathrm{http} / /$ banchedati.camera.it/AssembleaCostituente/>. Asimismo señalamos, Falzone, V., Palermo, F., Cosentino, F., La Costituzione della Repubblica italiana illustrata con i lavori preparatori, Milano, 1976)

13 Torres Del Moral, A., Constitucionalismo Histórico Español, Tirant lo Blanch, Madrid, 2004. 
Por otra parte, es significativo notar cómo, a la hora de describir las funciones legislativas y ejecutivas, el Constituyente de 1978 haya decidido emplear fórmulas que no aluden tan claramente al concepto de «Poder», prefiriendo a esta noción términos que describen fundamentalmente los órganos encargados de dichas funciones correspondientes (Título III «De las Cortes Generales», Título IV «Del Gobierno y de la Administración»).

¿Cuál puede haber sido la razón de esta singularidad?

La doctrina ha ofrecido distintas interpretaciones para aclarar esta circunstancia, es decir, para aclarar por qué la Constitución utiliza la expresión Poder sólo para aludir a la función judicial.

Así, algunos defienden la elección del Constituyente en razón del «carácter único» de la función judicial respecto a las funciones legislativa y/o ejecutiva que gozan también de una importantísima dimensión territorial que se plasma en los valores de la autonomía local y autonómica ${ }^{14}$.

Sin embargo, como recuerda FRIAS ${ }^{15}$, para una parte de la doctrina el empleo de la expresión judicial tiene como fundamento el hecho de resaltar la autonomía e independencia de la jurisdicción, como Poder y no solo como función ${ }^{16}$. Para otros el recurso al término «Poder Judicial» responde a la voluntad del Constituyente de reafirmar la garantía última de materialización del Estado Social y Democrático de Derecho al que se refiere el art. 1.1 de la Carta fundamental ${ }^{17}$.

Más allá del debate doctrinal, es imperativo acudir a la jurisprudencia del Tribunal Constitucional para entender el alcance de la expresión que introduce el Título VI de la Constitución de 1978. Así, en la Sentencia 108/1986, de 29 de junio, esa Corte pone en evidencia como «El Poder Judicial consiste en la potestad de ejercer la jurisdicción, y su independencia se predica de todos y cada uno de los jueces en cuanto ejercen tal función, quienes precisamente integran el Poder Judicial o son miembros de él porque son los encargados de ejercerla. Así resulta claramente del artículo 117.1 de la Constitución, con que se abre el Título VI de la misma dedicado al Poder Judicial.»

${ }^{14}$ Mosquera Sánchez, L., «La posición del Poder Judicial en la Constitución Española de 1978» en Constitución Española de 1978, Estudio Sistemático, Civitas, Madrid, 1980.

${ }_{15}$ Frias, E., «La Administración de Justicia», en Ortega, L. (dir.), Derecho Administrativo Autonómico de Castilla-La Mancha, Ediciones de la Universidad de Castilla-La Mancha, 2000, p. 202.

16 Almagro Nosete, J., «Poder Judicial y Tribunal de Garantías en la nueva Constitución», en Lecturas sobre la Constitución Española, UNED, 1, 1980.

17 Xiol Rios, L., González Rivas, J. J., Rodríguez Zapata Pérez, J., El Poder Judicial y su Consejo General en el Estado Social y Democrático de Derecho, Premios Poder Judicial. Consejo General del Poder Judicial, 1990. 
Por último, es oportuno volver a la doctrina y, más concretamente, a esa parte de la misma ${ }^{18}$ que pone el acento sobre el aspecto subjetivo del Poder Judicial, para afirmar que dicho Poder encarna, esencialmente, una estructura organizada cuyos protagonistas son los órganos llamados a administrar la Justicia. En nuestra opinión sería esta la lectura más fiel de la expresión contenida en el art. 117.1 CE -«integrantes del Poder Judicial»-, referida a Jueces y Magistrados. En este mismo sentido debería de interpretarse la letra del art. 122, referido al Consejo General del Poder Judicial (a partir de ahora, CGPJ), en el que se establece que «la Ley orgánica del poder judicial determinará la constitución, funcionamiento y gobierno de los Juzgados y Tribunales, así como el estatuto jurídico de los Jueces y Magistrados de carrera, que formarán un Cuerpo único, y del personal al servicio de la Administración de Justicia.»

\subsection{Los principios constitucionales que rigen la función jurisdiccional en la $C E$}

Entre los principios constitucionales que rigen el funcionamiento de la administración de Justicia en España, estimamos oportuno señalar algunos de ellos que destacan por su importante contenido de valor y que, por ello, contribuyen a definir el correcto alcance de la función judicial en este país. Hablamos, en otras palabras, del principio de legitimación democrática del Poder Judicial; del principio de unidad de la jurisdicción; del principio de responsabilidad y del principio de exclusividad.

\subsubsection{El principio de legitimación democrática del Poder Judicial y de sumisión del juez a la Ley}

Como es sabido, uno de los principios más importantes que vieron la luz a raíz de las primeras revoluciones liberales del siglo XVIII fue el principio de soberanía popular. Así, si el art. 3 de la Declaración de los Derechos del Hombre y del Ciudadano, solemnemente establecía que «la Nación es esencialmente la fuente de toda soberanía; ningún individuo ni ninguna corporación pueden ser revestidos de autoridad alguna que no emane directamente de ella»; hoy el art. 1.2 CE declara que «la soberanía reside en el pueblo español del que emanan los poderes del Estado».

En nuestro sistema constitucional, la legitimación democrática de la función judicial no se expresa en los mismos términos que caracterizan la función legislativa o ejecutiva. En efecto, en estos dos últimos casos, la sobera-

18 Sainz de Robles y Arozamena, F. C., «Poder Judicial y Consejo General del Poder Judicial», en Estudios sobre la Constitución Española. Homenaje al Prof. E. García de Enterría, Tomo VI, Civitas, 1991 
nía popular se manifiesta de forma patente a través de la elección directa de los representantes en las Cortes Generales por parte de quién esté legitimado al voto (Arts. 68 y $69 \mathrm{CE}$ ) o a través del vinculo de confianza que debe existir $-\mathrm{y}$ permanecer, si es posible- entre una parte de estos representantes (el Congreso de los Diputados) y el Gobierno (art. 99 CE).

Sin embargo, por lo que atañe a la función judicial, la legitimación democrática exigida por el art. 1.2 CE se plasma diversamente, trayendo origen en el principio de sumisión del juez a la Ley y a la Constitución (Arts. 9.1 CE y art. 117.1 CE), es decir, en el acto en el que se sustancia la voluntad general tras la conclusión del procedimiento legislativo ${ }^{19}$. Así pues, es en la Ley y exclusivamente en ella, donde el juez debe encontrar la solución al caso llevado a su conocimiento. Por ello, toda resolución jurisdiccional (sentencia, pero también auto, providencia, etc.) fundándose en la Ley, fruto de la voluntad popular expresada a través de representantes legítimos elegidos democráticamente, puede destacar por su carácter vinculante e imperativo ${ }^{20}$.

19 Este concepto es claramente expuesto en la «Exposición de Motivos» a la Ley Orgánica 6/1985, de 1 de julio, del Poder Judicial, cuando en ella se afirma que «El Estado de Derecho, al implicar, fundamentalmente, separación de los poderes del Estado, imperio de la Ley como expresión de la soberanía popular, sujeción de todos los poderes públicos, a la Constitución y al resto del ordenamiento jurídico y garantía procesal efectiva de los derechos fundamentales y de las libertades públicas, requiere la existencia de unos órganos que, institucionalmente caracterizados por su independencia, tengan un emplazamiento constitucional que les permita ejecutar y aplicar imparcialmente las normas que expresan la voluntad popular, someter a todos los poderes públicos al cumplimiento de la ley, controlar la legalidad de la actuación administrativa y ofrecer a todas las personas tutela efectiva en el ejercicio de sus derechos e intereses legítimos. El conjunto de órganos que desarrollan esa función constituye el Poder Judicial del que se ocupa el título VI de nuestra Constitución». Por otra parte, el mismo art. 1 de dicha Ley, retomando la fórmula del art. 117.1 CE, declara que «La justicia emana del pueblo y se administra en nombre del Rey por Jueces y Magistrados integrantes del Poder Judicial, independientes, inamovibles, responsables y sometidos únicamente a la Constitución y al imperio de la ley».

${ }^{20}$ Recordemos el tenor del art. $118 \mathrm{CE}$, por el que «Es obligado cumplir las sentencias y demás resoluciones firmes de los Jueces y Tribunales, así como prestar la colaboración requerida por éstos en el curso del proceso y en la ejecución de lo resuelto». Por otra parte, merece, en este contexto, volver el pensamiento de MONTESQUIEU y lo que vimos hablando de su teoría, recordando nuevamente las palabras que empleó para describir la función judicial «los jueces de la nación no son, según sabemos, sino la boca por donde habla la ley, seres inanimados que no pueden moderar ni su fuerza ni su rigor». (Del espíritu..., ob. cit., p. 237). Acerca de la legitimación democrática del Poder Judicial, podemos mencionar HitTERS, J. C., «Legitimación democrática del poder judicial y control de constitucionalidad», en Justicia: revista de derecho procesal, n. ${ }^{\circ} 2,1987$, pp. 421-434; BREY BlANCO, J. L., «La legitimación democrática de la función jurisprudencial y la elección de los vocales del CGPJ», en Revista general de legislación y jurisprudencia, ${ }^{\circ}{ }^{\circ} 2$, 2000, pp. 151-174; y también Moschella, G., «Función jurisdiccional y legitimación democrática», en Cuadernos de derecho público, n. ${ }^{\circ}$ 26, 2005, pp. 11-40. 
Por estas razones, el primer párrafo del art. 117 establece que «la Justicia emana del pueblo", empleando una fórmula que, lejos de ser puramente retórica, remite a un principio fundamental en todo Estado democrático y de Derecho: el dogma de la soberanía popular.

Desde esta perspectiva, es fácilmente comprensible porque los jueces deberán manifestar, a través de la motivación de sus sentencias, los razonamientos jurídicos y lógicos en los que se apoyan sus decisiones últimas ${ }^{21}$. Dicho principio se traduce, además, en la imposibilidad para el juez de desaplicar las normas previstas para el caso en aras de una presunta ilegitimidad constitucional de las mismas. En efecto, en estos casos, la coherencia del sistema ofrece al magistrado la posibilidad de elevar la duda de constitucionalidad al supremo juez de la Ley, es decir, al Tribunal Constitucional a través de la formulación de una cuestión de inconstitucionalidad ex art. $163 \mathrm{CE}^{22}$.

\subsubsection{El principio de responsabilidad}

La independencia del juez y su responsabilidad constituyen conceptos íntimamente relacionados.

Como es sabido, la Constitución exige al al juez de ser independiente y, por lo tanto, de administrar la Justicia aplicando exclusivamente un conjunto de preceptos legales que constituyen el fruto y la expresión de la voluntad general. Así, por estas mismas razones, el propio juez debe ser consciente de que, renunciado a su propia independencia, desatiende responsablemente la aplicación del marco legal, otorga prevalencia a otros principios ajenos al criterio legal $\mathrm{y}$, en definitiva, se aparta de la voluntad democrática.

Desde estas perspectivas, es posible afirmar que la independencia sirve para recordar al juez que su propia conducta, en el ejercicio de la función jurisdiccional, debe responder exclusivamente a unos cánones normativos preestablecidos.

${ }^{21}$ Así, como establecido por el art. 120.3 CE «Las sentencias serán siempre motivadas y se pronunciarán en audiencia pública», y por el art. 11.2 y 11.3 de la LO 6/1985 y por el art. 417.15 de la citada que considera como falta muy grave «La absoluta y manifiesta falta de motivación de las resoluciones judiciales que la precisen, siempre que dicha falta haya sido apreciada en resolución judicial firme». Recordamos, sobre este mismo tema, Milione Fugali, C., «El derecho a obtener una resolución de fondo en la jurisprudencia del Tribunal Europeo de Derechos Humanos y del Tribunal Constitucional español», en Perez Tremps, P., (coord.), La Reforma del Tribunal Constitucional: actas del V Congreso de la Asociación de Constitucionalistas de España, 2007, pp. 761-792.

22 Art. $163 \mathrm{CE}$ : «Cuando un órgano judicial considere, en algún proceso, que una norma con rango de ley, aplicable al caso, de cuya validez dependa el fallo, pueda ser contraria a la Constitución, planteará la cuestión ante el Tribunal Constitucional en los supuestos, en la forma y con los efectos que establezca la ley, que en ningún caso serán suspensivos». 
Que la función jurisdiccional constituya una «función responsable», la Constitución de 1978 lo pone de manifiesto, por una parte, garantizando en su art. 9.3 una serie de principios, entre los cuales destaca «la responsabilidad y la interdicción de la arbitrariedad de los Poderes públicos»; por otra, citando la responsabilidad en su art. 117.1, entre las características que deben acompañar jueces y magistrados en la administración de Justicia.

Por otra parte, cabe destacar cómo la norma llamada a desarrollar la materia judicial, es decir, la LO 6/1985, de 1 de julio, del Poder Judicial, rubrica su Título III «De la Responsabilidad de Jueces y Magistrados» (Arts. 405427), disciplinando, en dos Capítulos distintos, la «Responsabilidad penal» (Cap. I) ${ }^{23}$ y la «Responsabilidad civil» (Cap. II) ${ }^{24}$ que se resuelven, respecti-

${ }^{23}$ En materia de responsabilidad penal de los magistrados señalamos: LLARENA CONDE, P., «Consideración puntual de determinados aspectos relativos a la responsabilidad penal de jueces y magistrados», en Estudios de derecho judicial, n. ${ }^{\circ}$ 153, 2008 (Ejemplar dedicado a: La responsabilidad personal del juez), págs. 55-74; Sото NiETo, F., «La responsabilidad penal de los jueces y magistrados», en La Ley: Revista jurídica española de doctrina, jurisprudencia y bibliografía, n. ${ }^{\circ}$ 1, 1987, pp. 927-949; ORTEGA PÉREZ, F., «La exigencia de responsabilidad penal a jueces y magistrados: el antejuicio y su supresión», en Justicia: revista de derecho procesal, n. ${ }^{\circ}$ 1, 1997, pp. 165-184; ZARZALEJOS NiETo, J. M., El proceso penal contra jueces y magistrados: (la especialidad del antejuicio), Centro de Estudios Judiciales, Madrid, 1992; BACIGALUPO ZAPATER, E., «La responsabilidad penal de jueces y fiscales en el estado democrático de derecho», en DíEz RIPOLLÉs, J. L. (coord.), La ciencia del derecho penal ante el nuevo siglo: libro homenaje al profesor doctor don José Cerezo Mir, 2002, pp. 1191-1204; Sото NIETO, F., «La responsabilidad penal de los jueces y magistrados», en Terceras Jornadas de Derecho Judicial, Vol. 2, 1987, pp. 1135-1174; MARTínGRANIZO FERNÁNDEZ, M., «Reflexiones sobre la responsabilidad de jueces y magistrados», en Terceras Jornadas de Derecho Judicial, Vol. 2, 1987, pp. 1175-1204.

${ }^{24}$ En materia de responsabilidad civil de los magistrados señalamos: Alvarez SÁNCHEZ, J. I., «La responsabilidad civil de jueces y magistrados, abogados y procuradores», en Alvarez SÁnCheZ, J. I. (dir.), Cuadernos de derecho judicial, n. ${ }^{\circ}$ 7, 2003, pp. 19-66; FerNÁNDEZ Hierro, J. M., Responsabilidad civil judicial, Editorial Aranzadi, 1987; ATIENZA NAVArro, M. L., La responsabilidad civil del juez, Tirant lo Blanch, 1997; GArcía ManzANO, P., «Responsabilidad civil de Jueces y Magistrados», en Revista de administración pública, n. ${ }^{\circ} 117,1988$, pp. 99-152; GARCÍA VARELA, R., «La responsabilidad civil de los jueces y magistrados», en La Ley: Revista jurídica española de doctrina, jurisprudencia y bibliografía, n. ${ }^{\circ}$ 2, 1999, pp. 1857-1863; RAYÓN BALLESTEROS, M. C., «Aspectos sustantivos y procesales de la responsabilidad civil de los jueces y magistrados», en Anuario jurídico y económico escurialense, n. ${ }^{\circ}$ 29, 1996, pp. 301-342; RodríGUEZ AliQue, M. A., "Algunas reflexiones sobre la responsabilidad civil de jueces y magistrados», en Justicia: revista de derecho procesal, n. ${ }^{\circ}$ 3, 1988, pp. 613-626; PUIG I FERRIOL, L., «Apuntes sobre la responsabilidad civil de jueces y magistrados después de la vigencia de la Ley de Enjuiciamiento Civil 1/2000, de 7 de enero», en Revista xurídica galega, n. ${ }^{\circ}$ 30, 2001, pp. 13-30; y siempre del mismo autor, «Responsabilidad civil de los jueces y magistrados», en MorenO MARTÍNEZ, J. A. (coord.), Perfiles de la responsabilidad civil en el nuevo milenio, 2000, pp. 469488; Montero ArocA, J., «Sobre la responsabilidad civil de los Jueces», en Estudios de derecho procesal: en honor de Víctor Fairén Guillén, 1990, pp. 335-356. 
vamente, por la vía del proceso penal y por la vía del proceso civil. Asimismo, la Ley Orgánica recoge un tercer Capítulo dedicado a la «Responsabilidad disciplinaria» (Cap. III) de la que es competente el órgano de gobierno del Poder Judicial: el Consejo General del Poder Judicial (art. 122 CE) ${ }^{25}$.

Por último, la Constitución, en una dimensión íntimamente relacionada con el principio de responsabilidad, asegura en su art. 121 que «los daños causados por error judicial, así como los que sean consecuencia del funcionamiento anormal de la Administración de Justicia, darán derecho a una indemnización a cargo del Estado, conforme a la Ley». En este sentido, la Carta de 1978 introduce un mecanismo de indemnización a cargo del Estado (elevado a la calidad de «responsable objetivo») para las víctimas de perjuicios causados por errores judiciales o por funcionamiento anormal de la Justicia.

\subsubsection{El principio de exclusividad}

Cómo establece el art. 117.3 CE «el ejercicio de la potestad jurisdiccional en todo tipo de procesos, juzgando y haciendo ejecutar lo juzgado, corresponde exclusivamente a los Juzgados y Tribunales determinados por las leyes, según las normas de competencia y procedimiento que las mismas establezcan». Asimismo, el cuarto párrafo reitera que «los Juzgados y Tribunales no ejercerán más funciones que las señaladas en el apartado anterior y las que expresamente les sean atribuidas por ley en garantía de cualquier derecho.»

Estas dos normas consagran, en positivo y en negativo, el principio de exclusividad de la jurisdicción, por el que, por un lado, los jueces no pueden ejercer otra función que no sea la de administrar la Justicia, y por otro, nadie puede ejercer esta misma función encomendada a los jueces ${ }^{26}$.

${ }^{25}$ Más en concreto, la Ley Orgánica la LOPJ distingue entre tipos distintos de faltas disciplinaria, discriminando entre faltas leves (sancionadas con apercibimiento o sanciones pecuniarias); faltas menos graves (sanciones de mayor cuantía, traslados forzosos); y faltas graves (suspensión, separación definitiva de la carrera y pérdida del empleo). Acerca de la responsabilidad disciplinaria de jueces y magistrados, señalamos VACAS GARCÍA-ALós, L., «La responsabilidad disciplinaria de jueces y magistrados», en Estudios de derecho judicial, n. ${ }^{\circ} 153,2008$, pp. 267-340; y del mismo autor, «Ética pública, deontología judicial y responsabilidad disciplinaria de jueces y magistrados», en Manuales de formación continuada, n. ${ }^{\circ}$ 24, 2004, pp. 137-234; RuIZ VADILlo, E., MuÑoz CAMPOS, J., «La responsabilidad disciplinaria de los jueces y magistrados», en Terceras Jornadas de Derecho Judicial, Vol. 2, 1987, pp. 1245-1279; REQUERO IBÁÑEZ, J. L., «Responsabilidad disciplinaria de jueces y magistrados», en Actualidad administrativa, n. ${ }^{\circ} 27,1995$, pp. 433-454.

26 Acerca del principio de exclusividad de la jurisdicción, recordamos CHOCRÓN GIRÁLDEZ, A. M., «La exclusividad y la unidad jurisdiccionales como principios constitucionales en el ordenamiento jurídico español», en Boletín Mexicano de Derecho Comparado, n. ${ }^{\circ} 113$, mayo-agosto de 2005, pp. 651-687. 
El Tribunal Constitucional ha aclarado algunos de los efectos de dicho principios en dos Sentencias distintas. Así, en la Sentencia n. ${ }^{\circ} 1 / 1981$, de 26 de enero, relativa a la eficacia jurídica de los Tribunales Eclesiásticos, el supremo intérprete de la Constitución subrayó cómo dichos Tribunales carecen de facultades para que sus resoluciones produzcan efectos civiles en los casos de procesos canónicos de separación, afirmando que «los procesos de separación matrimonial, para que produzcan efectos civiles, tendrán que seguirse ante los jueces ordinarios, siguiendo lo dispuesto en el artículo 117.3 de la Constitución española y el artículo 51 de la LEC.»

Por otra parte, en la Sentencia n. ${ }^{\circ}$ 23/1985, de 15 de febrero, el Tribunal Constitucional reconoció, en materia de proceso penal, que «la fijación de los «hechos» del proceso, y la valoración o apreciación de los medios de prueba tendentes a definir la quaestio facti del proceso penal corresponde a la exclusividad del Juez que conoce la causa y sólo revisable [...] en las instancias superiores incardinadas en la organización judicial penal.»

\subsubsection{El principio de unidad de la jurisdicción y la dimensión territorial del Poder Judicial en nuestro Estado Autonómico}

$\mathrm{El}$ art. 117.5 CE establece que «El principio de unidad jurisdiccional es la base de la organización y funcionamiento de los Tribunales. La ley regulará el ejercicio de la jurisdicción militar en el ámbito estrictamente castrense y en los supuestos de estado de sitio, de acuerdo con los principios de la Constitución.»

Asimismo, el art. $122 \mathrm{CE}$, reenviando al legislador orgánico la determinación del funcionamiento, de la constitución y del gobierno de los Juzgados y Tribunales, aclara que los Jueces y Magistrados de carrera «formarán parte de un Cuerpo único».

Por su parte, la Ley Orgánica (a partir de ahora, LO) 6/1985, de 1 de julio, del Poder Judicial declara en la primera parte del art. 3.1 que «La jurisdicción es única y se ejerce por los Juzgados y Tribunales previstos en esta Ley ${ }^{27}$.

Como podemos ver, tanto la Constitución de 1978 como la legislación orgánica que desarrolla la materia judicial, dibujan dos características esenciales de la función jurisdiccional, es decir, su carácter unitario y, a la vez, su desconcentración, pues todo Juez o Magistrado que ejerce la jurisdicción es además representante del Poder Judicial.

${ }^{27}$ En realidad, numerosas otras normas son útiles para entender el alcance del principio de unidad del Poder Judicial. Así, por ejemplo, cabe recordar que el art. 122.2 CE indica que el gobierno de dicho Poder corresponde únicamente al Consejo General del Poder Judicial y que el art. 123.1 CE reconoce en el Tribunal Supremo «es el órgano jurisdiccional superior en todos los órdenes, salvo lo dispuesto en materia de garantías constitucionales». 
El principio de unidad, por otra parte, se sustancia en la prohibición de crear tribunales especiales o de excepción, es decir, tribunales convocados ad hoc o ad hominem y llamados a tratar y resolver casos determinados que se hayan producido antes de su convocación y, por lo tanto, en el más absoluto desprecio del criterio de predeterminación del juez.

Otra dimensión del principio de unidad de la jurisdicción es la que atañe a la repartición territorial del Poder. Así, si en las Comunidades Autónomas, a través de las cuales se organiza territorialmente el Estado español, asistimos a una separación en escala reducida de un Poder Legislativo (Parlamentos autonómicos) y de un Poder Ejecutivo (Gobiernos autonómicos), esto mismo no es posible predicarlo en relación a la función judicial. En efecto, la doctrina considera unánimemente que -rebus sic stantibus - el principio de unidad de la jurisdicción nos impide imaginar una descentralización del Poder Judicial en nuestro modelo territorial ${ }^{28}$.

Nos interesa, en este sentido, recordar la Sentencia del Tribunal Constitucional 31/2010, de 28 de junio, relativa a la impugnación del nuevo Estatuto Catalán, y en particular el Fundamento Jurídico n. ${ }^{\circ} 42$, por el que «la función jurisdiccional, mediante la que tales normas [estatales y autonómicas] adquieren forma y contenido definitivos, es siempre, y sólo, una función del Estado. En definitiva, si el Estado autonómico arranca con una Constitución única, concluye con una jurisdicción también única, conteniéndose la diversidad de órganos y funciones en las fases del proceso normativo que media entre ambos extremos. La unidad de la jurisdicción y del Poder Judicial es así, en el ámbito de la concreción normativa, el equivalente de la unidad de la voluntad constituyente en el nivel de la abstracción. La estructura territorial del Estado es indiferente, por principio, para el Judicial como Poder del Estado.»

Por otra parte, el mismo Tribunal Constitucional en su Sentencia 56/1990, de 28 de marzo, interpretando el reparto de competencias dibujado por el art. 149.1.5 CE, ya había señalado que, en relación con la materia judicial, dicho artículo «hace imposible [para las Autonomías] asumir cualquier competencia al respecto, ni a través de cláusulas, ni a través de otro mecanismo».

A la luz de esta jurisprudencia, entonces, resulta claro que la única norma constitucional en virtud de la cual la distribución territorial del poder produce algún reflejo sobre la materia judicial, es el citado art. 152.1 CE, párrafo segundo.

${ }^{28}$ En este sentido, Frias, E., «La Administración...», ob. cit., p. 203; VIrGala ForURIA, E., «El Poder Judicial en las comunidades autónomas», en IBARRA RoBLES, J. L., y Garcia Herrera, M. A., (Dir.), Estudios de derecho judicial. Ejemplar dedicado a: Poder Judicial y unidad jurisdiccional en el Estado autonómico, n. ${ }^{\circ}$ 90, 2006, pp. 402; AGUDO ZAMORA, M., «La configuración del Poder Judicial en el Estado Autonómico», Centro de Estudios Andaluces, n. ${ }^{\circ}$ 22, 2007, p. 4. 
Según este artículo «Un Tribunal Superior de Justicia, sin perjuicio de la jurisdicción que corresponde al Tribunal Supremo, culminará la organización judicial en el ámbito territorial de las Comunidades Autónomas. En los Estatutos de las Comunidades Autónomas podrán establecerse los supuestos y las formas de participación de aquéllas en la organización de las demarcaciones judiciales del territorio. Todo ello de conformidad con lo prevista en la ley orgánica del poder judicial y dentro de la unidad e independencia de éste.»

Este precepto deja suficientemente claros algunos aspectos que consideramos oportuno detallar. En primer lugar, en cada Comunidad Autónoma, debe existir un Tribunal Superior de Justicia competente por una serie de asuntos que se hallan descritos en los Arts. 73-77 de la LO 6/1985. Sin embargo, la doctrina, a la luz del dictado constitucional, considera de forma unánime que dichas instituciones representan órganos estatales que, simplemente, se ubican en las Comunidades Autónomas. A la luz de esta reconstrucción doctrinal, debemos concluir que ni tan siquiera la existencia de los Tribunales Superiores de Justicia constituye un argumento válido para afirmar que el modelo constitucional español conoce una verdadera distribución territorial del Poder Judicial29.

Desde otra perspectiva y por lo que concierne a las demarcaciones judiciales en los territorios autonómicos, las conclusiones no pueden ser distintas. Así, en la misma Sentencia 56/1990, el Tribunal Constitucional recuerda que el art. 152.1, apartado dos, representa fundamentalmente una «norma de remisión». En este sentido, este precepto, por un lado, atribuye a los Estatutos autonómicos la competencia sobre la regulación de una serie de conteni-

${ }^{29}$ Xiol Rios, J. A., «El papel constitucional del Tribunal Supremo», en GERPE LANDIN, M., (coord.), La posición del Tribunal Supremo en el Estado Autonómico. Seminario, Barcelona, 17 de mayo de 2007, Institut de Estudis Autonomics, Barcelona, 2008, p. 28. El autor recuerda que «El Tribunal Constitucional extrae la consecuencia (STC 25/1981, FJ 5) de que la relación de los órganos judiciales con la comunidad autónoma no es de pertenencia a una organización, sino de ubicación territorial. La unidad del poder judicial, pues, se erige en principio limitador frente a la diversidad propia del Estado compuesto». En este mismo sentido y, si cabe más, claramente, BACIGALUPO ZAPATER, E., «Tribunal Supremo y Tribunales Superiores de Justicia de las Comunidades Autónomas (desde la perspectiva del orden jurisdiccional penal)», en GERPE LANDIN, M., (coord.), La posición..., ob. cit., p. 52, recuerda que «Sin duda, el art. $152 \mathrm{CE}$ es ambiguo, pues pareciera que la organización y la jurisdicción de los tribunales superiores es cuestión del Estatuto y de la competencia de las comunidades autónomas, pero esto es sólo una apariencia. En la medida en la que la Administración de Justicia es nacional y los Estatutos son producto de una ley orgánica de la Cortes, aprobada mediante un procedimiento que bien podría ser denominado como de «codecisión», la primacía del Estado, surgida del art. 149, no experimenta una excepción en el art. 152.» Asimismo, GuzMAn FluJA, V., «El Tribual Superior de Justicia de Andalucía», en Terol Becerra, M. J., (coord.), Comentarios al Estatutos de Autonomía para Andalucía, Tirant Lo Blanch, Valencia, 2009, p. 443. 
dos («los supuestos y las formas de participación [de las Comunidades Autónomas] en la organización de las demarcaciones judiciales del territorio»), mientras por otro, remite a la propia Ley Orgánica del Poder Judicial la imposición de una serie de límites relativos a esas regulaciones ${ }^{30}$. Así, según el supremo interprete de la Constitución, la materia relativa a la demarcaciones judiciales constituye sí, una excepción respecto al principio por el que se impide a las Comunidades Autónomas asumir competencias en materia judicial. Sin embargo, es evidente que no resulta admisible fundar sobre un argumento tan débil ninguna teorización sobre la distribución territorial del Poder Judicial en España.

Para concluir nuestra exposición sobre el principio de unidad jurisdiccional, y sobre su articulación a nivel territorial, consideramos necesario hacer breve referencia a las fuertes contraposiciones doctrinales que se produjeron a raíz de la introducción de los Consejos de Justicia de las Comunidades Autónomas, consagrados en algunos de los -así llamados- «Estatutos autonómicos de segunda generación $»^{31}$.

Cabe, en primer lugar, mirar a la LO 6/2006, de 19 de julio, de reforma del Estatuto de Autonomía de Cataluña (EAC) y, más concretamente, a los Arts. 97-100 del mismo que describen la naturaleza y las competencias del Consejo de Justicia en esa Comunidad Autónoma. Las razones por las que mirar, principalmente, al Estatuto catalán de 2006 son evidentes. En primer lugar, se trata de entender que el modelo de Consejo de Justicia descrito por el EAC ha sido adoptado, en las formas y en los contenidos, también por otros Estatutos autonómicos con ocasión de sus reformas: así, in primis, por

${ }^{30}$ Así los expone el Tribunal Constitucional: «nos encontramos, pues, con el juego de tres normas, las cuales en el presente supuesto integran el bloque de la constitucionalidad: la Constitución, norma habilitante, que abre la posibilidad de que las Comunidades Autónomas, a través de sus respectivos Estatutos de Autonomía, asuman competencias en la organización de las demarcaciones judiciales; los Estatutos de Autonomía, normas a través de las cuales y con fundamento en la previsión constitucional, las distintas Comunidades Autónomas han asumido competencias en la referida materia; y la LOPJ que ha establecido el marco en el que las Comunidades Autónomas han de ejercer las competencias asumidas por los Estatutos de Autonomía con fundamento en la previsión constitucional, es decir, ha articulado el ejercicio de las mismas».

${ }^{31}$ Así, en primer lugar, debemos recordar el art. 33.3 de la LO 1/2006, de 10 de abril, de reforma del Estatuto de Autonomía de la Comunidad Valenciana; el art. 96 de la LO 6/2006, de 18 de julio, de reforma del Estatuto de Autonomía de Cataluña; el art. 96 de la LO 1/2007, de 28 de febrero, de reforma del Estatuto de las Illes Balears; el art. 144 de la LO 2/2007, de 19 de marzo, de reforma del Estatuto de Autonomía para Andalucía; el art. 64 de la LO 5/2007, de 20 de abril, de reforma del Estatuto de Autonomía de Aragón; el art. 42 de la LO 14/2007, de 30 de noviembre, de reforma del Estatuto de Autonomía de Castilla y León; y, finalmente, el art. 52 de la LO 1/2011, de 28 de enero, de reforma del Estatuto de Autonomía de la Comunidad Autónoma de Extremadura. 
el de Andalucía de 2007 (véanse, en particular, su art. 144). En segundo lugar, debemos recordar los efectos -inter partes, erga omnes e interpretativos- de la STC 31/2010, de 28 de junio, que, resolviendo el recurso de inconstitucionalidad interpuesto contra distintas normas del EAC, ha, de jure, sancionado la inconstitucionalidad de algunos preceptos relativos al Consejo de Justicia catalán ${ }^{32}$ y, de facto, de sus normas correspondientes en el Estatuto andaluz.

Así, para el Tribunal Constitucional, los Consejos de Justicia autonómicos no pueden constituir órganos de gobierno del Poder Judicial, paralelos y descentrados respecto al CGPJ, pues a la luz de la legislación actual, no existen premisas legales útiles para permitir una configuración de esas instituciones en estos términos.

Así lo manifiesta el Alto Tribunal cuando afirma que «ni otra ley que no sea la Orgánica del Poder Judicial puede determinar la estructura y funciones de aquel Consejo dando cabida, en lo que ahora interesa, y en su caso, a eventuales fórmulas de desconcentración que, no siendo constitucionalmente imprescindibles, han de quedar, en su existencia y configuración, a la libertad de decisión del legislador orgánico con los límites constitucionales antes expresados».

Parece evidente, entonces, que el asunto relativo a los Consejos de Justicia Autonómicos ha constituido un caso emblemático de «huida hacia adelante» de los legisladores estatuyentes que no han sabido ni considerado oportuno esperar una necesaria reforma Ley Orgánica del Poder Judicial para poder dar vida a esos órganos autonómicos que -de jure condido- no tienen derecho de ciudadanía en nuestro sistema jurídico y constitucional.

\section{LA NECESIDAD DE JUSTICIA EN NUESTRAS SOCIEDADES DEMOCRÁTICAS ACTUALES}

Es difícilmente cuestionable la tesis por la que la idea de Justicia, su percepción e incluso su función han profundamente evolucionado en nuestras sociedades en esta última mitad de siglo.

32 Así, Castella Andreu, J. M., («La Sentencia del Tribunal Constitucional 31/2010, sobre el Estatuto de Autonomía de Cataluña y su significado para el futuro del Estado autonómico», en Fundación Ciudadanía y Valores, Septiembre 2010, pág. 11) señala que «El Tribunal declara inconstitucionales las referencias al Consejo como órgano delegado del Consejo General del Poder Judicial para el gobierno del Poder Judicial en el ámbito catalán (art. 97); también son nulas buena parte de sus atribuciones (art. 98.2 a, b, c, d y e, y 3)9; los incisos «y con la participación del Consejo de Justicia de Cataluña» del art. 95.5 y 6 , en relación con el nombramiento de los presidentes del TSJ y los presidentes de Sala del TSJ que propone el CGPJ; la referencia al Presidente del TSJ como Presidente del Consejo de Justicia de Cataluña (art. 99.1); y el recurso en alzada de los actos del Consejo de Justicia ante el CGPJ (art. 100.1)». 
Merece la pena recordar las palabras de FiX-ZAmudio y Cossío DíAz ${ }^{33}$ cuando afirman que «la función jurisdiccional de nuestra época se encuentra sujeta a una profunda revisión en virtud de su creciente complejidad, ya que lo que se habia concebido de manera tradicional como una actividad puramente técnica de resolución de conflictos jurídicos se ha transformado en uno de los servicios públicos esenciales del Estado contemporáneo.»

Estas consideraciones llevan GARCÍA DE ENTERRÍA a reconocer que en nuestras sociedades modernas se está realizando un proceso de transformación del Estado de Derecho en Estado de Justicia ${ }^{34}$, tesis que el mismo TOHARIA retoma, recordándonos cómo la Justicia adquiere en la actualidad un protagonismo social antes desconocido, como consecuencia de un conjunto de factores de naturaleza evidentemente distinta (políticos, sociales, culturales, etc.) ${ }^{35}$.

Así, según apuntan dichos juristas, el deseo de una correcta aplicación de las normas jurídicas constituye un sentimiento irrenunciable para todo conjunto ciudadano, para una ciudadanía que, respecto al pasado, es hoy más formada y más informada, en definitiva, más consciente del alcance de sus prerrogativas basadas en el Derecho y por ello, más propensa a acudir al sistema de Justicia para conseguir la satisfacción de sus pretensiones por medio de los jueces ${ }^{36}$.

${ }^{33}$ Fix-Zamudio, H., Cossío DíAz, J. R., El poder judicial en el ordenamiento mexicano, México Fondo de Cultura Económica, 1996, p. 15.

${ }^{34}$ García De Enterría, E., Democracia, jueces y control de la Administración, Civitas, $3^{\text {a }}$ ed., Madrid, 1995.

${ }_{35}$ TOHARIA, J. J., La imagen de la Justicia en la Sociedad Española - Séptimo barómetro de opinión, Consejo General del Poder Judicial, Madrid, 2000, pp. 5-24. Este jurista señala, entre otros, cuatro procesos de cambio que, en su opinión, dibujan un nuevo papel institucional de la Justicia en la realidad actual. En primer lugar, TOHARIA pone en evidencia el espectacular crecimiento del sistema legal y su tendencia a abarcar todos los aspectos más comunes e incluso más complejos de la convivencia civil; por otro lado este jurista subraya la emersión de una nueva cultura jurídica más consciente de sí y que tiende a la afirmación, reclamación y defensa de los derechos individuales; en tercer lugar, otro proceso fundamental en nuestro contexto social es la «judicialización de la vida pública» por la que los Tribunales de Justicia amplían su ámbito de acción a espacios que antes se consideraban fundamentalmente políticos; por último, TOHARIA hace referencia a la mayor importancia que cobra el sistema de Justicia en el correcto desarrollo económico del país.

${ }^{36}$ Estas consideraciones llevan FRIEDMAN, L. M., (Total Justice, Russell Sage, New York, 1994) a hablar de «Justicia total» para describir una tendencia propia de estos últimos 50 años en los que, como TOHARIA eficazmente describe (La imagen...ob. cit., pág. 15) «El azar, el accidente, lo imprevisible o lo inevitable tienden a ser factores de disculpa cada vez menos aceptables socialmente. La idea ahora dominante es que tras todo daño o perjuicio hay una culpa y por tanto una obligación de resarcimiento. Y lo que se espera del sistema legal es que garantice que alguien esté obligado a prever toda posible contingencia negativa, del tipo que sea, que su evitación sea competencia y responsabilidad de alguien, y que caso de producirse un daño alguien haya de compensar a las personas que resulten afectadas.» 
Desde estas perspectivas, el sentimiento primordial de Justicia es hoy más fuerte, mientras que, de manera inexorable, los ámbitos de nuestra convivencia que se encuentran regulados por normas jurídicas se hacen, cada vez, más amplios.

La necesidad de Justicia de nuestras sociedades democráticas es, hoy día, más presente $\mathrm{y}$, por ende, presupone el máximo esfuerzo de los Poderes públicos para asegurar un sistema judicial eficaz y efectivo, para asegurar, en otras palabras, un servicio público - esencial y necesario- provisto de las máximas garantías previstas por la Ley.

A través de las páginas que siguen y tras una breve descripción de los aspectos fundamentales que caracterizan y definen el Estado Social, nos proponemos demostrar cómo la Justicia y su administración, tradicionalmente configuradas en términos de Poder por la doctrina liberal, adquieren hoy una fisionomía renovada, cercana a la de un verdadero servicio público que todo Estado Social debería proveer a sus ciudadanos respetando unos principios y garantías orientados al logro de los niveles más altos de calidad y eficacia.

\subsection{Estado Social y función judicial}

Tras la Segunda Guerra Mundial, la cláusula del Estado Social hace su aparición en las Constituciones de la mayor parte de los países europeos ${ }^{37}$, con formas distintas y con proclamaciones más o menos manifiestas y explicitas $^{38}$.

37 Así, GonzÁlez Moreno, B., El Estado Social. Naturaleza jurídica y estructura de los derechos sociales, Civitas, Madris, 2002, p. 29. Sin embargo, algunos estudiosos consideran posible adelantar a la segunda mitad del siglo XIX las primeras formas de Estado Social o «asistencial». En este sentido, Conti, F., SiLEI, G., (Breve storia dello Stato Sociale, Roma, Carocci) reconocen que la primera manifestación de Estado Social moderno se debe al canciller alemán BISMARCK y a la introducción de un sistema de seguros obligatorios para los casos de enfermedades, al que seguirán seguros contra infortunios, pobreza, viejez, discapacidad y muerte del cabeza de familia.

${ }^{38}$ Pensamos, por ejemplo, al art. 20 de la Ley Fundamental de la República Federal de Alemania que recita «La República Federal de Alemania es un Estado federal democrático y social»; o al art. 1 de la Constitución de la República Francesa de 1958 por el que «Francia es una República indivisible, laica, democrática y social que garantiza la igualdad ante la ley de todos los ciudadanos sin distinción de origen, raza o religión y que respeta todas las creencias»; o al más reciente art. 1 de la Constitución Española de 1978 que proclama a «España como un Estado social y democrático de Derecho que propugna como valores superiores de su ordenamiento jurídico la libertad, la justicia, la igualdad y el pluralismo político».

En este catálogo, la República italiana parece ser una excepción, pues la Constitución Italiana de 1948 en ningún momento proclama Italia, de manera manifiesta, Estado social. Sin embargo, como puso en evidencia Mortati, C., («art. 1», en BrancA, G. (coord.), Commentario della Costituzione. Principi Fondamentali, Vol. 1, Zanichelli \& Il Foro Ita- 
No es un caso que este concepto de Estado, o esta orientación ideológica que asume la organización estatal haga su aparición en un momento de la historia de Europa (la segunda mitad del siglo XX) en el que las reivindicaciones sociales de las clases más desfavorecidas se hacen más fuertes.

Si con la afirmación del Estado liberal algunos principios democráticos basilares habían visto, por vez primera, su afirmación -es suficiente pensar en el derecho de sufragio, al derecho a la igualdad formal o al derecho a la libertad consagrados en las primeras declaraciones de derechos o en las primeras Constituciones liberales- la situación económica, social y cultural de los ciudadanos europeos de finales del siglo XIX había demostrado que tales logros, lejos de determinar una mejora de las condiciones de vida de las masas trabajadoras, se habían quedado sólo en un plano meramente teórico.

La importancia de frenar la tendencia expansiva de los principios liberales, en el ámbito político y económico, acompañada por la necesidad de establecer una serie mínima de garantías formales para garantizar el ejercicio efectivo de la igualdad y de libertad constituyeron algunas de las premisas para la afirmación del Estado social.

Así, como señalado anteriormente, en la fase sucesiva al segundo conflicto mundial, desde un punto de vista político, los mayores agentes sociales (partidos políticos, sindicatos, organizaciones empresariales) encontraron una acuerdo de síntesis en torno a una idea fundamental: conyugar dos principios aparentemente antitéticos -el principio de libertad económica y el de igualdad social- para identificar en dicha síntesis una nueva base legitimadora del Estado ${ }^{39}$.

La aparición del Estado social, de este modo, marca el ocaso del Estado del «laissez faire» en ámbito económico, es decir, del Estado que postula una autorregulación del mercado. Así, el Estado abandona toda actitud pasiva para hacerse mediador entre los agentes económicos y sociales, para promover la negociación y el encuentro de soluciones compartidas. De igual modo, en un sistema de producción de masas, el Estado desarrolla una función irrenunciable como factor de estímulo de la demanda y como agente estabilizador del empleo, de las relaciones salariales, etc ${ }^{40}$.

liano, Bologna-Roma, 1975, p. 45) que la Carta de 1948 no exteriorizara con una formula expresa el carácter social de la República italiana no legitima ninguna duda en mérito.

39 García Cotarelo, M., Introducción a la Teoría del Estado, Ed. Teide, Barcelona, 1981; asimismo, Agudo Zamora, M. J., Milione, C., Mérida Díaz, S., La aportación de UGT-Andalucía a la construcción del Estado del bienestar en Andalucía, FUDEPA, 2010, p. 22.

${ }^{40}$ Como señala AÑón RoIG, en este contexto el Estado desarrolla una función fundamental para la regulación de la demanda agregada, la estabilización de los ciclos económi$\cos$, la intermediación para la obtención de mano de obra, la socialización de gran parte de los costes privados y el arbitraje del conflicto social para mantener la paz social. AÑón RoIG, M. J., GARCíA AÑón, J., Lecciones de derechos sociales, Tirant Lo Blanch, Valencia, 2002. 
Cómo podemos constatar, la fórmula del Estado social postula un mayor compromiso y una mayor capacidad de intervención en las dinámicas sociales, con el fin de conseguir lo que RosanVALLON describe eficazmente cómo un "programa ilimitado: liberar a la sociedad de la necesidad y del riesgo» ${ }^{41}$.

Estas consideraciones, llevaron a HELLER a establecer un binomio inescindible entre el Estado y su función social al afirmar que esta es «la misión que tiene que cumplir como factor, como unidad de acción en la conexión de la actividad social» $\rangle^{42}$.

Conceptos que se reafirman y refuerzan en el pensamiento de PÉREZ LuÑo por el que el Estado es el principal actor social llamado a asumir «la responsabilidad de proporcionar a la generalidad de los ciudadanos las prestaciones y servicios públicos adecuados para subvenir sus necesidades vitales, es decir, [la responsabilidad de velar] por lo que la doctrina germana ha calificado de procura existencial» $\rangle^{43}$.

Si bien los contornos de esta «procura existencial» no pueden que ser definidos en relación a los aspectos concretos y a los problemas actuales de la sociedad en la que el Estado se encuentra a actuar, GARCÍA PELAYo consigue aclarar algunas de las medidas que constituyen el eje de esta función social: la elaboración de instrumentos aptos a hacer posible la existencia humana; la adopción de medidas dirigidas a garantizar la seguridad del individuo, así como la prevención de las situaciones de necesidad; la elaboración de políticas orientadas a la protección del medio ambiente; o la fijación de una serie de prestaciones sociales tales como el salario mínimo, el acceso al mundo laboral, el acceso a una vivienda, la protección de los ancianos, de los menores, de los minusválidos, o de los colectivos vulnerables, etc. ${ }^{44}$

En efecto, este constituye el terreno sobre el que se desarrolla la actividad del Estado social, en la persecución de tres objetivos esenciales distintos: la seguridad económica y social; la reducción de la desigualdad; la lucha a la pobreza.

Más concretamente, respecto a estos ejes fundamentales, es suficiente recordar cómo el art. 2 del Tratado de Roma, de 25 de marzo de 1957, por el que se constituye la Comunidad Económica Europea, reconoce en una «elevación acelerada del nivel de vida» de los ciudadanos de los Estados miembros uno de los objetivos principales de la Comunidad misma. Igualmente, el art. 3 del mismo Tratado, determinando la creación del Fondo Social Euro-

${ }^{41}$ Rosanvallon, P., La crise de l'Etat-providence, Ed. du Seuil, Paris, 1981, p. 33.

${ }^{42}$ Heller, H., Teoría del Estado, Fondo de Cultura Económica, México, 1974.

43 Pérez Luño, A. E., Los derechos fundamentales, V Ed., Tecnos, Madrid, 1993, p. 193

${ }^{44}$ García Pelayo, M., Las trasformaciones del Estado Contemporáneo, Alianza Universidad, Madrid, 1985, pp. 29-30. 
peo, pone en evidencia cómo su objeto es el de «mejorar las posibilidades de empleo de los trabajadores y contribuir a la elevación de su nivel de vida.» ${ }^{45}$

Cabe recordar, la opinión de BRIGGS y DE PICó I LÓPEZ por los que el Estado de bienestar no representa sólo un Estado de servicios sociales dirigidos al uso de recursos humanos para abolir la miseria y asistir a los más desfavorecidos, sino que constituye un «Poder organizado y usado deliberadamente a través de la política y la administración en un esfuerzo para modificar el juego de las fuerzas del mercado al menos en tres direcciones: primero, para garantizar a los individuos y familias una renta mínima independientemente del valor de mercado de su trabajo o su propiedad; segundo, reducir la amplitud de la inseguridad para facilitar a individuos y familias satisfacer ciertas contingencias sociales que de lo contrario conducen a crisis individuales y familiares; $y$, tercero, para asegurar que a todos los ciudadanos sin distinción de status o clase les sean ofrecidos los mejores estándares disponibles en relación a cierta gama acordada de servicios sociales $\rangle^{46}$.

A partir de estas últimas reflexiones se hace posible reinterpretar, en un sentido distinto y diverso, las teorías relativas a la función judicial.

$\mathrm{Si}$ es cierto que el Estado social o Estado del bienestar es por definición aquella organización que pretende ofrecer a sus ciudadanos unos servicios esenciales inspirados a criterios de calidad -merece la pena recordar la expresión de BRIGGS, «los mejores estándares disponibles»- pues, en nuestra opinión, resulta difícil defender que el valor de estas mismas afirmaciones no concierne también a la función judicial.

De este modo, siguiendo GonZalez Moreno, es imposible pensar que esta configuración de la realidad política y civil que llamamos «Estado social» no considere cómo uno de sus objetivos prioritarios la aplicación del Derecho, la defensa de la ciudadanía y, por ende, el afianzamiento de un sistema judicial capaz de contribuir al logro de los propósitos comunes. Así, como el mismo

${ }^{45}$ Igualmente relevantes son los Arts. 117 y 39 del mismo Tratado. En concreto, la primera norma concerniente al caso de los trabajadores, reconoce «la necesidad de promover la mejora de las condiciones de vida y de trabajo de los trabajadores, a fin de conseguir su equiparación por la vía del progreso»; mientras la segunda norma, en materia de objetivos de la política agrícola, declara que uno de ellos será el de garantizas un nivel de vida equitativo a la población agrícola, en especial mediante el aumento de la renta individual de los que trabajan en la agricultura.

El conjunto normativo del Tratado, permitirá hablar del reconocimiento implícito del derecho a un nivel de vida suficiente, cuyo contenido mínimo coincidiría con el contenido del art. 11 del Pacto internacional de Derechos Económicos, Sociales y Civiles, de 19 de diciembre de 1966, es decir, con el derecho a la alimentación, ropa y vivienda suficientes. Vd. Agudo Zamora, M. J., Milione, C., Mérida Díaz, S., La aportación..., ob. cit., p. 22.

${ }^{46}$ PICó I LóPEZ, J., Teorías sobre el Estado del Bienestar, Siglo XXI de España Ed., Madrid, 1987, p. 133. 
GONZALEZ MORENO ${ }^{47}$ afirma, una de las facetas más importantes de la procura existencial del Estado social afecta, sin duda, a «la seguridad de los distintos aspectos vitales en la sociedad nacional, que incluye no sólo la defensa exterior, sino también la seguridad interior frente al delito y la subversión.».

Es desde estas perspectivas y estas bases dogmáticas que consideramos posible ampliar a la administración de Justicia y a su función en el Estado social, este carácter de servicio público y esencial para toda la comunidad civil.

\section{2. ¿Es el poder judicial un verdadero poder? Hacia una nueva configuración de la administración de justicia}

Sin duda alguna, toda elaboración doctrinal haya intentado determinar, en términos concretos y efectivos, la importancia de la Justicia en los contextos democráticos, coinciden en un punto: el Derecho y su aplicación garantizada por el sistema de Justicia representan bienes de suma importancia para toda organización estatal.

El mecanismo más eficaz de conservación y perpetuación de dicho bien consiste en una correcta administración de Justicia, presupuesto esencial de toda libertad y progreso. Por todo ello, es posible afirmar que la Justicia representa el fundamento de toda res pública ${ }^{48}$.

Como hemos podido comprobar a lo largo de estas páginas, en los Estados democráticos la aplicación del conjunto normativo constitutivo del ordenamiento jurídico - expresión auténtica de la voluntad general consagrada en la Ley- constituye una tarea encomendada a lo que se define como un «Poder» funcionalmente único y orgánicamente múltiple: el Poder Judicial.

Así, en nuestros modelos constitucionales, por un lado encontramos la actividad de producción normativa encomendada a los órganos legislativos -Parlamentos nacionales y territoriales-, mientras que por otro, la función de dirección política y administrativa de la cosa pública se confía en el Gobierno. En estos órganos se plasma y cobra vida lo que es posible definir cómo el «momento político» del Estado, un conjunto de funciones que se condensan en el ejercicio de una discrecionalidad de naturaleza ideológica, generadora de decisiones políticas que no encuentran otros límites sino en lo constitucionalmente admisible y en lo coyunturalmente oportuno.

La antítesis del «momento político», sin embargo es representado por los órganos constitutivos del Poder Judicial que simbolizan «el momento jurídico» del Estado ${ }^{49}$. Dichos órganos democráticos - pues llamados a aplicar el

${ }^{47}$ GonzÁlez Moreno, B., El Estado..., ob. cit., p. 46.

${ }^{48}$ Santosuosso, F., Il Consiglio Superiore della Magistratura. Principi e Precedenti. Legge istitutiva 24 marzo 1958, n. 195, Ed. Giuffré, Milano 1958, pp. 3-7.

49 Como afirma Pérez Royo, J., («El proyecto de Constitución del Derecho público como ciencia en la doctrina alemana del siglo XIX», en Revista de Estudios Políticos, n. ${ }^{\circ}$ 
Derecho y sometidos únicamente al mismo- representan instrumentos imprescindibles para nuestras sociedades, pues ante ellos un vasto número de conflictos entre particulares, finalmente encuentra su solución jurídica.

Así, si «en una sociedad organizada jurídicamente todos deben actuar jurídicamente y alguien debe determinar cuándo se actúa asi $\rangle^{50}$, jueces y magistrados representan esos sujetos institucionales encargados de realizar dicha determinación a través del análisis, interpretación y aplicación al caso concreto de las normas jurídicas abstractas.

En este sentido, el Poder Judicial realiza, en el marco de todo Estado de Derecho, una función de garantía democrática irrenunciable: contribuye a asegurar que la soberanía popular, cristalizada en normas a través del procedimiento legislativo, pueda producir sus efectos en el ámbito jurídico y en la vida real. Un sistema político verdaderamente democrático sólo puede serlo en la medida en que la participación ciudadana actúa como presupuesto para la creación de normas de Derecho inspiradas a criterios de Justicia, y sólo a condición de que exista un conjunto de órganos judiciales llamados a dar aplicación y -finalmente- eficacia concreta a estas normas.

Este postulado implica, entonces, que la desconfianza en la función judicial y en su capacidad de llevar a cabo esa difícil labor, no puede que determinar el ocaso del sistema democrático, ante la incapacidad del mismo de garantizar la vigencia y la efectividad de la ley y del Derecho ${ }^{51}$.

Así, sobre estas bases, podemos afirmar que el núcleo esencial de la función jurisdiccional atribuida al Poder Judicial en ello consiste, en la correcta interpretación y aplicación de las normas jurídicas.

Como hemos visto hablando del pensamiento de MonTESQUiEU, las teorías que predican la separación de los Poderes del Estado constituyen algunos

1, 1978, p. 6) «el Estado moderno [...] es ante todo una realidad política, en cuya constitución no interviene el Derecho de manera determinante. El Derecho interviene a posteriori como elemento de conformación, de configuración de esa realidad política que es el Estado. Se trata, por tanto, de ver qué conexión existe entre estos dos momentos: el momento político y el momento jurídico...». Por otra parte y desde otra perspectiva, el mismo Tocqueville, A., (La democracia en América, Alianza Ed., Madrid, 1980, Vol. 1, p. 254) afirmaba que «casi no hay cuestión política en los Estados Unidos que no se resuelva, pronto o tarde, en una cuestión judicial».

50 Navarrete Barrueto, J., «El poder del Poder Judicial», en Revista chilena de derecho, Vol. I, núm. 1, 1974, p. 74.

${ }^{51}$ En este mismo sentido se expresa SHuck, P. H., («El Poder Judicial en una democracia», en SELA (Seminario en Latinoamérica de Teoría Constitucional y Política), Papers, n. ${ }^{\circ} 31,2004$, p. 1) cuando rotundamente afirma que «sin tribunales no hay gobierno $\mathrm{y}$, ciertamente, no hay democracia», aunque también añade «incluso, regímenes no democráticos como la Alemania Nazi, la China Comunista y la antigua Unión Soviética han acudido a los tribunales como mecanismo de ayuda para implementar, de manera impositiva, políticas públicas de carácter arbitrario, así como para hacer cumplir tales dictámenes particulares en la medida en la que dichos tribunales lo permitían». 
de los dogmas más han influido en la construcción de nuestro constitucionalismo moderno.

Sin embargo, más de tres siglos más tarde y después de la consolidación de nuestros modelos democráticos, es legítimo preguntarse qué queda de esos postulados concebidos a lo largo del siglo XVIII, y si no cabe la oportunidad de revisarlos para que puedan responder mejor a nuestras exigencias actuales.

Un dato de partida parece irrefutable: en nuestros modernos Estados constitucionales la idea de un «Poder» encargado de la función judicial, es mayoritaria y casi incontrovertible, de modo que, plantear una alternativa a esas posturas doctrinales no solo puede parecer, en principio, algo desacralizante sino incluso una auténtica herejía ${ }^{52}$.

Sin embargo, es interesante constatar que la configuración actual de la función judicial en términos de «Poder», se debe fundamentalmente a dos tipos distintos de premisas (algunas de carácter dogmático y otras de naturaleza empírica) que no sólo es posible, sino también oportuno confutar.

Así, desde un punto de vista dogmático, es posible constatar que la función judicial ha adquirido la dignidad de «Poder» apoyándose -de manera falaz, es oportuno precisarlo- en la teoría de la separación de poderes de MONTESQUIEU.

Una lectura atenta de «Del Espíritu de las Leyes» no nos permite afirmar que el ilustre pensador francés imaginara o deseara entregar la administración de justicia a un conjunto de funcionarios o burócratas. Como hemos podido evidenciar en el párrafo inicial, MoNTESQUIEU deseaba que el «Poder de juzgar» estuviera totalmente desligado de cualquier condición profesional, quería sin embargo, que dicha función pudiera ser desarrollada por comunes ciudadanos extraídos al azar del pueblo, para que éstos actuasen sólo como «boca de la ley», es decir, sin ningún poder de mitigar o refrenar la fuerza del Derecho ${ }^{53}$.

Por estas razones, este pensador negaba la posibilidad de configurar el «Poder de juzgar» en los mismos términos del legislativo o del ejecutivo, $\mathrm{y}$ por estas mismas razones lo etiquetaba con una serie de adjetivos incontrovertibles: «nulo» e «invisible». En otras palabras, para MONTESQUIEU, el «Poder de juzgar» no era, ni podía constituir, un verdadero poder.

Sin embargo, la errónea - desde nuestro punto de vista-interpretación del pensamiento del filosofo francés y su perpetuación en términos equivocados

${ }^{52}$ Por todo ello, como recuerda Toharia, J. J., («La imagen de la Justicia en la Sociedad Española. Séptimo barómetro de opinión», en Informe CEDOJ, Consejo General del Poder Judicial E-62J181, Noviembre 2000, pág. 31) «incluir a la Justicia en la nómina de servicios públicos obligados a rendición periódica y detallada de cuentas [resulta] una osadía o un despropósito».

${ }^{53}$ Montesquieu, C.-L. de S., Del espíritu..., ob. cit., p. 237. 
a lo largo del tiempo, representan sólo algunas de esas premisas que estimamos necesario confutar.

Como señala una parte de la doctrina ${ }^{54}$, otra razón de considerar que la función judicial constituye un poder del Estado se fundamenta en una desacertada interpretación del proceso de evolución del liberalismo francés.

Así, como indica TAJADURA TEJADA, buena parte de la responsabilidad de equiparar la función judicial a un «poder», traería origen de un enésimo «malentendido»: olvidar que los dos modelos tradicionales de Justicia -el modelo jacobino y el modelo estadounidense- han servido, cada uno, para dar respuestas diversas a reivindicaciones igualmente distintas, otorgando carácter democrático a la función judicial por vías netamente opuestas.

Así, como es sabido, la soberanía popular en el modelo de justicia de Norteamérica se manifiesta a través de procesos electorales directos o indirectos -es decir, por medio de representantes- que otorgan a los jueces una legitimación democrática fuerte, manifiesta e inmediata. En razón de ello, entonces, es posible afirmar que el modelo estadounidense configura la función judicial como un verdadero «Poder del Estado», reconociendo a todo juez no sólo la prerrogativa y el deber de interpretar y aplicar las normas jurídicas, sino también el derecho de desaplicarlas -sin trámite intermedio alguno- cuando su ejecución pueda producir consecuencias de dudosa legitimidad constitucional.

Sin embargo, el modelo francés -forjado a raíz de las revoluciones liberales y generalmente adoptado en toda Europa- arranca de presupuestos radicalmente distintos: el «supuesto poder de los jueces» consiste sólo y exclusivamente en aplicar al caso concreto una norma general y abstracta; en ser «la boca de la ley» a la que están sometidos hasta el punto tal de deber manifestar su sumisión en la motivación de las resoluciones judiciales adoptadas, hasta el punto tal de no poder desaplicar directamente dichas normas, ni tan siquiera cuando sobre ellas recaigan dudas de constitucionalidad.

Así, ante este panorama, como afirma TAJADURA TEJADA «sólo en virtud de una licencia terminológica podemos referirnos [en nuestros modelos europeos] a la Justicia como Poder ${ }^{55}$ y es por este mismo motivo que -con excepción de la Constitución española de 1978-, la gran mayoría de las Constituciones europeas prefieren no adoptar la expresión «Poder Judicial» al momento de disciplinar el funcionamiento de esta función del Estado ${ }^{56}$.

${ }^{54}$ TAjadura Tejada, J. «Reflexiones en torno a la configuración del Poder Judicial como servicio público», en UNED. Teoría y Realidad Constitucional, n. ${ }^{\circ} 8-9,2 .^{\circ}$ semestre 2001/1. ${ }^{\text {er }}$ semestre 2002, pp. 177-200; TOHARIA, J. J., Opinión Pública y Justicia, Consejo General del Poder Judicial, Madrid, 2001, pp. 31-46; y sobre todo, APARICIO, M. A., Prologo a Simon, D., La independencia del Juez, Ariel, Barcelona, 1985, p. VII.

55 Tajadura Tejada, J., «Reflexiones...», ob. cit., p. 190.

56 Véase la nota a pie de página $n^{\circ} 11$. 
Resulta evidente, entonces, que nuestro modelo constitucional carece de justificaciones dogmáticas fuertes en fuerza de las que proclamar que la labor judicial constituye un clásico poder del Estado. Sin embargo, si esta carencia se produce desde la vertiente dogmática, desde un punto de vista empírico y práctico resulta mucho más difícil dudar del «efectivo poder» de los que se encuentran investidos nuestros jueces y magistrados. Todo resulta manifiesto sobre la base de consideraciones elementales.

En primer lugar, la idea de un «juez boca de la ley» es evidentemente utópica e ilusoria. En nuestra opinión, el inmenso poder de la función judicial descansa en la libre interpretación del Derecho por parte de todo juez o magistrado. Así, la supuesta sumisión a la Ley del Poder Judicial encuentra su punto de equilibrio -o de desequilibrio- en la facultad de extrapolar de la norma jurídica aplicable al caso concreto, un determinado significado en lugar que otro, sin que dicha labor pueda considerarse sometida a vínculos, con la única excepción de lo establecido por el art. 5 de la LOPJ.

En segundo lugar, nadie puede olvidar que la labor judicial, en virtud de la interpretación y aplicación del Derecho, acaba determinando el destino y la suerte de un número infinito y muy distinto de cuestiones de carácter público, social y económico. Por todo ello, el mismo TOHARIA puede afirmar que, en nuestro contexto actual, estamos asistiendo a un proceso lento e inevitable de «judicialización de la vida pública» es decir, a la «expansión del radio de acción de los tribunales de Justicia a asuntos de naturaleza política» ${ }^{57}$. Por otra parte, no es posible olvidar que una rápida y eficaz administración de Justicia produce repercusiones muy relevantes desde el punto de vista económico y, por lo tanto, en el crecimiento y desarrollo de un Estado ${ }^{58}$.

A estas consideraciones se añaden otras, como las que se detienen en el análisis de la función judicial como verdadero factor mediático en el seno de nuestras sociedades modernas. Así, aunque buena parte de la doctrina estime que el ámbito de la Justicia resulta poco apto a los mecanismos propios del mundo de la información ${ }^{59}$, es indudable que el Poder Judicial ha adquirido un fuerte protagonismo público. Así lo manifestó el mismo Presidente del CGPJ,

57 TOHARIA, J. J., La imagen..., ob. cit., p. 17 y ss.

${ }^{58}$ Como afirma Campos Moreno, J. C., («Modernización de la Justicia: un presupuesto de futuro», en Presupuesto y gasto público, n. ${ }^{\circ}$ 58/2010, Secretaría General de Presupuestos y Gastos, Instituto de Estudios Fiscales, p. 29), «se advierte cómo paz social, desarrollo y justicia se encuentran en una indisociable relación de dependencia». Si cabe, más claramente LösING, N., «Estado de Derecho, seguridad jurídica y desarrollo económico», en Anuario iberoamericano de justicia constitucional, n. ${ }^{\circ}$ 6, 2002, pp. 273-298), afirma que el Estado debe garantizar la seguridad jurídica, pues sólo en virtud de esta misma es posible determinar un clima de confianza que constituye el presupuesto básico de todo desarrollo económico.

59 En este sentido, ZarZALejo Soler, J., «Justicia mediática: tutela o ilusión», en Revista de la Facultad de Ciencias Jurídicas y Políticas de la Universidad Central de Ve- 
DIVAR BLANCO, afirmando que «el ejercicio de la jurisdicción [ha adquirido] un protagonismo público -o si se prefiere, mediático-inusual, poco imaginable décadas atrás, que hace que el trabajo de los jueces [...] trascienda en muchos casos del simple interés jurídico presente en los procesos [...] este nuevo panorama plantea nuevas variables cualitativamente relevantes en la relación entre el juez y la sociedad. La presencia de la justicia y de sus protagonistas en el espejo público de la sociedad, no deseada por muchos jueces [...] debe, no obstante, ser aceptada sin recelos, asumiendo con normalidad que probablemente nos encontramos ante un camino sin retorno. $\rangle^{60}$

Como es evidente, todas estas argumentaciones que podemos considerar «de naturaleza empírica», (la importancia de la labor de interpretación del Derecho; las repercusiones políticas, sociales, públicas y económicas de la Justicia y su reflejo mediático) contribuyen, en su conjunto, a reforzar las tesis que describen la función judicial como un Poder público.

Sin embargo, como hemos podido constatar, desde un punto de vista dogmático, afirmar que en nuestro modelo constitucional la función judicial constituye un Poder del Estado, no encuentra suficientes argumentos a su respaldo.

\section{CONCLUSIONES. LA JUSTICIA: UN SERVICIO PÚBLICO ESENCIAL}

Las reflexiones y los razonamientos que hemos venido desarrollando a lo largo de este trabajo, quieren constituir los presupuestos sobre los que basar una nueva configuración de la función judicial, una configuración más coherente con los principios democráticos de nuestro Estado y más próxima a la idea de «servicio público esencial».

En efecto, es suficiente considerar el alcance que la doctrina tradicional reconocer al concepto de «servicio público» para constatar que esta misma noción puede aplicarse a la función judicial. Así, para HAURIOU, es posible afirmar que un «servicio público» es «un servicio técnico prestado al público de una manera regular y continua para la satisfacción de una necesidad pública y por una organización pública ${ }^{61}$, y que sus características principales consisten en la generalidad, uniformidad, regularidad y continuidad ${ }^{62}$.

nezuela, n. ${ }^{\circ} 130,2007$, p. 329 y ss.; Movilla Álvarez, C., El compromiso cívico del juez demócrata: la labor periodística, Barcelona, Ronsel, 1999.

${ }^{60}$ Divar Blanco, C., «El Juez en la sociedad», CGPJ, disponible en línea en http:// www.poderjudicial.es/stfls/cgpj/PRESIDENCIA/DISCURSOS\%20DEL\%20PRESIDENTE/FICHERO/DiscursoApertura2010_1.0.0.pdf, págs. 19-20 (última consulta, 29 noviembre 2013).

${ }^{61}$ Hauriou, M., Precís de Droit Administratif, Paris, 1919, IX Ed., p. 44.

${ }^{62}$ Gordillo, A. A., Tratado de Derecho Administrativo, Tomo II - La defensa del usuario y del administrado, VII Ed., Fundación de Derecho Administrativo, Buenos Aires, 2006, p. 186. 
En fuerza de todo ello, TOHARIA recuerda que un juez no representa un poder, ni directa, ni indirectamente la voluntad popular, desarrollando el papel propio de «un funcionario altamente especializado a quien está encomendado un servicio público de particular relevancia, pero servicio público al fin $»^{63}$.

Como hemos visto, la razón por la que, a partir de la aprobación de nuestra Constitución en 1978, la función judicial ha adquirido -de manera injustificada, lo repetimos- las connotaciones propias de un «Poder público», descansan todas en la voluntad de ofrecer a dicha función una mayor y más fuerte garantía de exclusiva sumisión del juez a la Ley. De ahí, entonces, la creación de un órgano constitucional como el Consejo General del Poder Judicial, encargado de salvaguardar la independencia judicial no sólo respecto al resto de poderes, sino frente a todos, incluso respecto a los demás órganos jurisdiccionales del Estado.

Sin embargo, ese deseo legítimo de desvincular la función judicial de los demás poderes públicos ha acabado adquiriendo unos tintes confusos en nuestro contexto constitucional. Así, para una parte de la doctrina, la «independencia funcional» del Poder Judicial (es decir, la independencia de ejercicio en la labor de administración de la Justicia) se ha transformado en «independencia de origen». De este modo, como afirma TAJADURA TEJADA ${ }^{64}$, la Justicia ha adquirido la apariencia de «una institución que despliega su actividad al margen de los mecanismos de control propios de un Estado democrático. La Justicia independiente se desliza por este camino hacia la Justicia irresponsable.»

Esta configuración ha determinado una serie de consecuencias y efectos negativos que, inevitablemente, por una parte, han interesado algunos aspectos funcionales y organizativos de la administración de Justicia -no última, la excesiva duración de los procesos- y, por otra, han apartado el Poder Judicial del binomio Gobierno-Parlamento ${ }^{65}$.

A la luz de estas consideraciones cabe preguntarse si una total o parcial reconfiguración del Poder Judicial en términos de «servicio público» podría servir a mitigar algunos de los problemas que la Justicia en España ha experimentado a lo largo de estos últimos años ${ }^{66}$.

${ }^{63}$ TohaRIA, J. J., La imagen... ob. cit., p. 37, recordando, a continuación, que por todo ello «la vigente Constitución Francesa elude utilizar la palabra «pouvoir» para aludir a la Justicia, utilizando en cambio el mismo término que empleara Montesquieu: «puissance»!).

${ }^{64}$ TAjadura TejadA, J., «Reflexiones...», ob. cit., p. 196, citando en realidad, TOHARIA, J. J., «La independencia y la buena Justicia», en Derecho y sociedad, n. ${ }^{\circ}$ 3, 1999.

${ }_{65}$ En este sentido, Tajadura TejadA, J., Reflexiones...», ob. cit., p. 197,

${ }^{66}$ Como evidenciado por los Presidentes de los Tribunales Superiores de Justicia reunidos en Albacete los días 3-5 de octubre de 2012, al denunciar las carencias estructurales, organizativas, tecnológicas y presupuestarias que presenta la Administración de 
En nuestra opinión, la respuesta a esta pregunta debe ser positiva...con unos matices.

En primer lugar, reconocer que la función judicial no es ni puede constituir un Poder, significaría adoptar una postura más coherente con el modelo de Justicia por el que hemos optado a partir de 1978. Como sabemos y hemos visto, el modelo español en nada responde a las características del sistema norteamericano donde, en virtud de una legitimación democrática directa, los jueces sí representan un legítimo y verdadero «Poder Judicial».

Sin embargo, es cierto que estas disquisiciones doctrinales relativas a la posición constitucional del juez y a su mayor o menor emanación democrática, pueden importar en la medida en que una determinada configuración del modelo en lugar que otra, pueda servir a garantizar que la labor del sistema judicial sea más rápida, eficaz, eficiente y acorde a la legalidad.

Así, adoptar una configuración compatible con la noción de «servicio público», por un lado, podría permitir a la ciudadanía exigir a jueces y magistrados el respeto de unos «estándares de calidad» en el desarrollo de sus tareas y, por otra parte, consentiría a los miembros de la función judicial reivindicar con más fuerza y legitimación los medios humanos y materiales necesarios para ofrecer su servicio de manera conforme a dichos estándares.

En nuestra opinión hablar de la necesidad de alcanzar determinados niveles de calidad en la prestación de los servicios de Justicia no significa degradar la función judicial ni adoptar una perspectiva mercantilista asimilable a las que practican las empresas para medir sus resultados. Hablar de «estándares de calidad» para nosotros significa simplemente cumplir con el mandato constitucional consagrado en la Constitución y, particularmente, el art. 24 de la misma. Significa, en otras palabras, cumplir con los requisitos y las garantías que configuran la «tutela judicial efectiva» en todas sus vertientes.

Sin embargo, es evidente que despojar la función judicial del crisma de «poder» podría determinar un grave desequilibrio del sistema de check and balances descrito por MONTESQUIEU, que acabaría por registrar un neto predominio de los Poderes de naturaleza política (legislativo y ejecutivo). Así, desde nuestro punto de vista, no es posible defender la noción de "servicio público de Justicia» sin prever, simultáneamente, la adopción de instrumentos que vuelvan a reforzar los mecanismos constitucionales en defensa de la autonomía e independencia de la Magistratura.

Por lo tanto, no sólo sería necesario redefinir las competencias del CGPJ sino también el mecanismo a través del que se realiza la designación de sus miembros, con el fin de garantizar, por un lado, una mayor carácter democrático y, por otro, un mayor alejamiento de las lógicas partidistas propias de cierta política.

Justicia, situación que se ha visto agravada por una completa paralización de las inversiones en Justicia debido a la importante crisis económica. 
Más allá de estas propuestas, lo que sí es imperativo es abandonar la idea de una Justicia defectuosa -por lo tanto, mejorable-, y sin embargo, irreformable. JOUBERT afirmaba que «la Justicia es la verdad en acción», quizás ya haya llegado el tiempo de actuar.

TITLE: The Judicial Function in the frame of the Spanish Social and Regional State: Power or Public Service?

RESUMEN: El deseo común y compartido de una correcta aplicación de las normas jurídicas juega un papel fundamental en un proceso de transformación que está interesando, en la actualidad, nuestras estructuras democráticas. Estamos viviendo un proceso de transición entre el Estado de Derecho y el Estado de Justicia, con una ciudadanía más formada, más informada y, en definitiva, más consciente del alcance de sus prerrogativas basadas en el Derecho. Por otra parte, si la ciudadanía acude con más desenvoltura al sistema de Justicia, es también porque los ámbitos de nuestra convivencia que se encuentran regulados por normas juridicas se hacen, cada vez, más amplios. Todo ello presupone el máximo esfuerzo de los Poderes públicos para asegurar que el sistema judicial sea eficaz, efectivo y respondiente a las garantías y a los principios que nuestra Constitución exige para nuestro Estado social y autonómico. Entre todos ellos destacan el principio de legitimación democrática y de sumisión del juez a la ley, el principio de responsabilidad, el principio de exclusividad, el principio de unidad de la jurisdicción y la dimensión territorial del Poder Judicial en nuestro Estado compuesto. Ante este panorama en evolución, cabe preguntarse si tiene sentido configurar la función judicial como un Poder Estatal, siguiendo la tradición de Montesquieu. En realidad, seguimos equiparando la función judicial a un "poder» sobre la base de un "malentendido». Hemos olvidad que los dos modelos tradicionales de Justicia - el modelo jacobino y el modelo estadounidense- han servido, cada uno, para dar respuestas diversas a reivindicaciones igualmente distintas, otorgando carácter democrático a la función judicial por vías netamente opuestas. Así, como es sabido, la soberanía popular en el modelo de justicia de Norteamérica se manifiesta a través de procesos electorales directos o indirectos-es decir, por medio de representantes-que otorgan a los jueces una legitimación democrática fuerte, manifiesta e inmediata. Sin embargo, el modelo francés -forjado a raiz de las revoluciones liberales y generalmente adoptado en toda Europa-arranca de presupuestos radicalmente distintos: el «supuesto poder de los jueces» consiste sólo y exclusivamente en aplicar al caso concreto una norma general y abstracta; en ser «la boca de la ley» a la que están sometidos. Nuestro planteamiento es el de volver a configurar la función judicial por lo que realmente es o debería ser: un servicio público esencial que el Estado debe proporcionar a la ciudadanía acorde a una serie de principios constitucionales y estándares de calidad. Este estudio, reflexiona sobre estas cuestiones.

PALABRAS ClaVES: Poder, judicial, servicio, público, principios, Constitución. 
ABSTRACT: The common will of a correct application of the law, plays a central role in the process of transformation which is actually going on in our democratic societies. We are witnessing the evolution from the "rule of law» to the "State of justice» with a citizenship which is more conscious and aware of their own prerogatives based on Law. Moreover, the areas of our coexistence which are regulated by legal rules are, increasingly, broader. This is also a cause of this evolution. This whole situation requires the maximum effort of Public Powers to ensure that the judicial system is efficient, effective as stated by our Constitution and by those principles that define our Autonomic State. Among them stand out the principle of democratic legitimacy and judges submission to the law, the principle of responsibility, the principle of exclusivity, the principle of unity of the jurisdiction and the territorial dimension of the judiciary in our regional State. Given this evolution process, it is worth to consider whether it makes sense to set the judicial function as a State Power, following the Montesquieu's tradition. We still consider the judiciary as a "power» because of a «misunderstanding». We forgot that the two traditional models of Justice-the Jacobin model and the North American-has been useful to address different issues and to give different answers to equally distinct claims, granting a democratic status to the judicial function in opposite ways. Thus, as is well known, the democratic legitimation of the judiciary in North America occurs through direct or indirect elections which permit to configure it as a real power. However, the French model that followed the XVIII century revolutions and that has been generally adopted throughout Europe, is grounded on different premises: the "supposed power of the judges» lies exclusively in the application of a general and abstract rule to the case; in being "the mouth of the law» to which they are subjected. Our approach is to reconfigure the judiciary for what it really is or it should be: an essential public service that the State should provide the public according to a series of constitutional principles and quality standards. This study reflects on these issues.

KEYWORDS: Power, judiciary, service, public, principles, Constitution.

RECIBIDO: 13.10 .2014

Aceptado: 26.11.2014 